\title{
Smooth transition or permanent exit? Evidence on job prospects of displaced industrial workers
}

\section{Daniel Oesch* and Isabel Baumann}

Life Course and Inequality Research Centre (LINES), Swiss National Centre of Competence in Research LIVES, University of Lausanne

*Correspondence: daniel.oesch@unil.ch

\begin{abstract}
This article examines the job prospects of displaced industrial workers in Switzerland. Based on a survey of 1,203 workers who were dismissed after their manufacturing plants closed down, we analyse the determinants of re-employment, the sector of re-employment and the change in wages. Two years after displacement, a majority of workers were back in employment: $69 \%$ were re-employed, $17 \%$ unemployed and $11 \%$ retired. Amongst re-employed workers, two thirds found a job in manufacturing and one third in services. Contrary to a common belief, low-end services are not the collecting vessel of redundant industrial workers. Displaced workers aged 55 and older seem particularly vulnerable after a plant closes down: over 30\% were long-term unemployed, and those older workers who found a new job suffered disproportionate wage losses. Advanced age-and not low education - appears as the primary handicap after mass redundancy.
\end{abstract}

Keywords: unemployment, manufacturing, labour markets, wages, political economy, economic sociology

JEL classification: J63, J65, M51

\section{Introduction}

Few economic trends preoccupy observers of social change as much as deindustrialisation and the steady loss of jobs in manufacturing. Scholars of political economy are particularly pessimistic about the job prospects of displaced industrial workers: early retirement in the best case, long-term unemployment in the worst case (Bonoli, 2007, p. 498). Their pessimism is rooted in the view that 'most skills acquired in manufacturing travel very poorly to service occupations' (Iversen and Cusack, 2000, p. 326). As a consequence, low-skilled blue-collar workers should find it exceedingly hard to adjust to similarly low-skilled service jobs (Iversen and Cusack, 2000, p. 326). Since job growth takes place in services, this seriously curtails their re-employment chances. 
These gloomy expectations have been echoed within academia and wider public circles. Yet they are clearly at odds with the growing literature on labour market flows. Recent evidence suggests that each year more than $20 \%$ of all jobs in affluent countries are created or destroyed - and around one third of all workers are either hired or separate from their employers annually (OECD, 2009, p. 119). Moreover, a substantial share of these worker flows are not from declining to expanding sectors but take place within narrowly defined industries (Greenaway et al., 2000, p. 61). This finding is in line with the fact that many workers are recruited by firms that are contracting, just as workers often exit firms that are expanding (Lane et al., 1996, p. 111).

The dead-end view of displaced industrial workers held in political economy is thus difficult to reconcile with constant labour market churning as described by the job flow literature. At the same time, both research strands focus on aggregate changes in sectoral employment and not on unemployed workers. It is thus an open question as to whether displaced industrial workers are ejected permanently from the labour market or whether job flows carry them back to work.

An ideal setting to address this question is the closure of a manufacturing plant, where an exogenous event leads to the dismissal of the entire labour force and obliges workers to find a new source of income-from work or welfare. We use this setting to analyse the labour market transitions of displaced industrial workers. Based on an individual-level survey on mass redundancy from five industrial plants in Switzerland, we first examine where workers went after their plant closed down: did they find a job, remain unemployed or go into retirement? We then analyse the sector in which re-employed workers took up a job-and the quality of this new job. Our objective is to shed light on industrial workers' postdisplacement destinations and identify the individual characteristics that explain the successful transition to a new job.

Mass redundancy in manufacturing is likely to affect worker sub-categories differently. The political economy view expects displaced white-collar workers and women to fare better than displaced blue-collar workers and men. These groups are considered to possess skills and capabilities that enable them to transit more easily to service jobs (Nickell, 2001). Job prospects are thus held to be truly bleak for male blue-collar workers only-yet they make up a large share in industrial plants.

Labour economists expect the re-employment chances of displaced workers to primarily hinge on education. The thesis of skill-biased technological change predicts workers with low levels of education to struggle more to return to a job than highly educated workers (Berman et al., 1998). In parallel, life course sociologists point to the paradox that many firms employ older workers, but do not hire older workers. When an industrial plant closes down, the most vulnerable group may thus be older workers (Knuth and Kalina, 2002). 
Our article addresses these issues as follows: Section 2 reviews the literature on the link between structural change and workers' labour market transitions. Section 3 presents our survey data and discusses the institutional context of the Swiss labour market. The ensuing sections present the empirical evidence on three different dimensions of the post-displacement transition: Section 4 on the re-employment status, Section 5 on the sector of re-employment and section 6 on the qualitywages and contract type-of the post-displacement job. Section 7 summarises our findings and highlights their policy implications.

\section{Hypotheses about displaced workers' job prospects}

Over the past four decades, employment in manufacturing has decreased constantly under the influence of automation and international trade. Whilst there is abundant macro-level evidence documenting this trend in the employment structure (e.g., Oesch and Rodriguez Menes, 2011), much less is known about how structural change from manufacturing to services comes about at the micro-level of individual workers. Cohort renewal certainly plays a role, as older birth cohorts leave the workforce and retire, whilst younger generations enter the labour market and take up different occupations (Blossfeld, 1986, p. 212). However, this process alone is probably not sufficient to ensure structural change. Accordingly, workers also need to switch between occupations and sectors over their career (Korpi and Mertens, 2004, p. 91). The thorny question is whether the main category hit by structural change, production and craft workers, is able to participate in this adjustment process or whether deindustrialisation means downwards mobility and labour market exclusion for them. On this subject, opinions in the social sciences strongly diverge.

The bleakest view is held by scholars studying welfare states and production regimes. Two of the field's prominent representatives maintain that 'for many, loss of employment in the traditional sectors [manufacturing] entails complete removal from the active labour force' (Iversen and Cusack, 2000, p. 313). Their pessimism rests on the idea that industrial workers lack transferable skills, as services and manufacturing are separated by 'a particularly thick skill boundary' (Iversen, 2001, p. 53). This expectation of an insurmountable skill barrier has clear policy implications. To bring industrial workers back into work, governments must turn to low-end services for employment opportunities. However, since industrial workers' productivity in service tasks is expected to be very low, these workers will only be hired if there is an expanding low-paid service sector. For this sector to expand, wages in low-end services must be allowed to trail behind the rest of the economy. Accordingly, the bitter medicine against industrial unemployment is an increase in wage inequality (Iversen and Wren, 1998, p. 512). 
A more optimistic prediction about displaced workers' job prospects emerges from the literature on job flows. In affluent countries, new recruitments and separations represent together each year close to one third of dependent employment. This means that annually about $15 \%$ of all matches between employers and workers are destroyed and simultaneously offset by a similar number of new matches between different employers and workers (OECD, 2009, p. 123). A substantial share of these worker flows are not from manufacturing to services, but take place within manufacturing (Greenaway et al., 2000, p. 61). In effect, although structural change comes about because there are small net flows from declining towards growing sectors, worker flows are far larger within than across sectors (OECD, 2009, p. 151). Moreover, worker flows are by no means solely directed away from manufacturing towards services but are bi-directional. A study of West Germany during the 1970s and 1980s suggests that $18 \%$ of all job moves lead workers from manufacturing to private services. But at the same time, $14 \%$ of moves go the opposite way, leading workers from private services to manufacturing jobs (Korpi and Mertens, 2004, p. 96).

Modern labour markets are thus subject to an impressive amount of worker-job match creation and destruction each year. However, sizeable jobs flows by themselves do not guarantee smooth transitions in the labour market. Workers who leave declining sectors are not necessarily the same workers who take up jobs in expanding sectors. Indeed, job-to-job flows may play only a minor role for net changes in sectoral employment. More important for sectoral change seem to be flows into and out of non-employment. These flows comprise the entry of new cohorts into the labour market on the one hand and the exit of older cohorts to unemployment or retirement on the other (Greenaway et al., 2000, p. 65; Bachmann and Burda, 2009, p. 56).

In this context the analytical leverage provided by plant closure and worker displacement proves useful. Of course, displacement is a phenomenon worth studying in its own right: it disrupts lives, disappoints hard-earned expectations, wastes human resources and possibly adds to long-term unemployment (Fallick, 1996, p. 5). Beyond that, it presents a laboratory for how industrial workers respond to structural change. Manufacturing is the sector where workers are most likely to experience plant closure and displacement (Cha and Morgan, 2010, p. 1141). Since plant closure leads to the dismissal of all workers independently of job performance, it largely_although not completely (Schwerdt, 2011) — avoids the threat of selectivity bias which arises when firms let go their least productive workers only.

The two views of constant job flows and thick skill boundaries imply very different job prospects for displaced workers. From the perspective of job flows, reemployment rates after displacement are likely to be sizeable-except if all the job turnover takes place through cohort renewal. In contrast, the view of a thick skill boundary holds employability in services to be key for displaced workers' 
job prospects (Iversen and Cusack, 2000)—and comes to pessimistic conclusions concerning men and blue-collar workers. Recent technological change is seen as biased against low-skilled men and in favour of low-skilled women as firms' labour demand has increased for tasks typically associated with female socialisation, such as dealing with people, training and teaching, counselling and caring (Black and Spitz-Oener, 2010, p. 129, Oesch, 2013, pp. 136-7). In contrast, demand has fallen for tasks requiring arm-hand steadiness, manual dexterity or operation monitoring. These tasks, typically done by men in production jobs, have proven much easier to automate. Women thus have the advantage over men of greater employability in the expanding service sector, notably in social and personal services.

An expanding service sector may primarily favour not displaced women but white-collar workers. The literature on mass redundancy suggests that displaced workers succeed in limiting earnings losses as long as they take up a job in the same sector (Neal, 1995, p. 658, Cha and Morgan, 2010, p. 1137). Thereby, they continue to benefit from the returns of their sector-specific skills. On the contrary, if displaced workers transit to a job outside of their contracting sector, they likely face wage losses-except if they move sector but stay in the same occupation (Haynes et al., 2002, p. 249). Accordingly, workers whose occupations allow for movement between sectors without necessitating a change in occupation should be at an advantage over those whose occupations are closely tied to manufacturing. Managers, bookkeepers and secretaries are examples of the former; electricians, welders and assemblers examples of the latter. White-collar workers therefore seem more likely than blue-collar workers to be able to transit from manufacturing to services without changing occupation.

Whilst gender and occupation may matter, education is often held to be the key determinant of re-employment chances. The thesis of skill-biased technological change implies that the value of education has risen in the labour market. In the context of mass redundancy, education is likely to improve job prospects more in a new sector than in the old sector. In the old sector, indicators such as work history and employer recommendations are of great relevance. In the new sector, educational attainment may serve as a decisive signal both for current productivity and the future learning abilities (Fallick, 1993, p. 317). This expectation is in line with the finding from the USA that low-skilled workers are hardest hit by industrial restructuring (DiPrete and Nonnemaker, 1997, p. 402). Differential re-employment chances of white- and blue-collar workers may then simply be rooted in different levels of education.

A last explanation argues that the biggest impediment to re-employment for displaced workers is not the lack of education but advanced age (Chan and Stevens, 2001; Knuth and Kalina, 2002; Couch and Placzek, 2010). Older workers should find it particularly hard to be re-employed for two reasons (Daniel and 
Table 1 Overview of the hypotheses

\begin{tabular}{|c|c|c|c|}
\hline Hypothesis & Theory & Focus & Predicted outcome \\
\hline $\mathrm{H} 1$ & $\begin{array}{l}\text { Job flows and } \\
\text { smooth } \\
\text { transitions }\end{array}$ & Job-to-job transitions & $\begin{array}{l}\text { Smooth re-employment under } \\
\text { stable macro-economic } \\
\text { conditions }\end{array}$ \\
\hline $\mathrm{H} 2$ & $\begin{array}{l}\text { Job flows and } \\
\text { cohort renewal }\end{array}$ & $\begin{array}{l}\text { Flows in and out of } \\
\text { non-employment }\end{array}$ & $\begin{array}{l}\text { Structural change is absorbed by } \\
\text { older workers who opt for (early) } \\
\text { retirement }\end{array}$ \\
\hline H3 & Political economy & Deindustrialisation & $\begin{array}{l}\text { Re-employment for female } \\
\text { white-collar, persistent un- } \\
\text { employment for male blue-collar }\end{array}$ \\
\hline $\mathrm{H} 4$ & $\begin{array}{l}\text { Skill-biased } \\
\text { technological } \\
\text { change }\end{array}$ & Education & $\begin{array}{l}\text { Low (intermediary) re-employment } \\
\text { rates for low-educated } \\
\text { (mid-educated) workers }\end{array}$ \\
\hline H5 & $\begin{array}{l}\text { Internal labour } \\
\text { markets }\end{array}$ & Age & $\begin{array}{l}\text { Smooth transition for most workers, } \\
\text { but not for older workers who } \\
\text { face long-term } \\
\text { unemployment }\end{array}$ \\
\hline
\end{tabular}

Heywood, 2007, pp. 36-7). First, they often possess great experience and knowledge, but these capabilities come largely with increased firm-tenure and cannot be transferred easily to another firm. When separated from their firm, older workers lose their productivity advantage and thus constitute expensive job candidates. Second, the hiring of older workers blocks internal career ladders and renders a firm's internal labour market less efficient. It thus runs contrary to the logic of long-term employment relationships, whereby employers use delayed compensation schemes based on seniority to motivate younger workers to pursue a career within their firm. Displaced older workers may thus face the choice between long spells of unemployment, large wage losses or involuntary early retirement (Knuth and Kalina, 2002).

Based on these ideas, our study examines five hypotheses about the job prospects of displaced industrial workers. Table 1 gives a schematic overview. The job flow literature gives rise to two hypotheses. Hypothesis 1 highlights the constant turnver of workers and predicts smooth re-employment for displaced workers. Hypothesis 2 expects structural change to primarily come about through cohort renewal and is thus more pessimistic about displaced workers' re-employment prospectsnotably about those of young and mid-aged workers, older workers being able to exit to retirement. Hypothesis 3 focusses on deindustrialisation and expects smooth re-employment patterns only for women in white-collar occupations, whereas persistent unemployment should be the more likely outcome for male 
blue-collar workers. Hypothesis 4 builds on the thesis of skill-biased technological change and expects education to be the prime determinant of workers' reemployment chances, predicting gloomy prospects for the low educated. Finally, Hypothesis 5 expects the greatest disparity in re-employment rates between age cohorts. Whilst younger cohorts should experience smooth transitions, older workers are held to be particularly vulnerable.

\section{Data, measures and institutional context}

Most studies of displaced workers are based on either administrative data or household surveys. Both data sources have disadvantages. Administrative data tend to have little information on worker characteristics and do not distinguish postdisplacement outcomes beyond employment and non-employment. Household surveys typically cover only a small number of displaced workers and do not distinguish between workers displaced because of restructuring and workers displaced for other reasons. Not knowing the cause of displacement is problematic, as the analysis of displaced workers should focus on mass redundancies where the entire plant closed down. Otherwise, selectivity becomes an important issue as firms may dismiss the least productive workers, whilst holding on to their most valuable employees.

We try to address these difficulties by conducting our own survey on industrial workers who were laid off after their plant closed down. Thereby, we follow a tradition of papers studying displaced workers on the basis of a subpopulation of firms (see Kriechel and Pfann, 2005 for the Netherlands; Trotzier, 2005 for France; Jolkkonen et al., 2012 for Finland). Our survey covers the workforces of five mid-sized manufacturing firms in Switzerland which either closed down a plant or ceased their activity altogether in 2009 or 2010.

Plant 1 was part of a multi-national corporation in machine tool manufacturing. It closed its production site over a period of 10 months and displaced 170 workers with 3 months of advance notice. Collective bargaining led to a generous social plan, including termination pay and early retirement for workers displaced 4 years before reaching the official retirement age. Plant 2 was a Swiss printing company which announced insolvency and basically shut down its operations overnight, dismissing all of its 260 employees_-with no social plan whatsoever. Plant 3 was part of a multi-national corporation producing chemicals and shut down in January 2009, displacing 430 workers with 4 months of advance notice and a social plan providing early retirement for workers 2 years before reaching the official retirement age. Plant 4 was a Swiss company producing printing machines which ceased its activities gradually and displaced its 320 workers with 5 to 9 months of advance notice. The social plan included early retirement for workers 57 years or older ( 7 to 8 years before the official retirement age). Finally, Plant 5 was part of a multi-national corporation producing metal and plastic components 
which displaced all its 200 workers over a period of 6 months. The social plan included termination pay and the option of early retirement-yet with relatively low benefits. None of the five companies provided specific training measures for their workers.

These plant closures took place in a context of comparatively low, but increasing unemployment. During the financial crisis, the Swiss unemployment rate increased from $3.4 \%$ in 2008 to $4.3 \%$ and $4.5 \%$ in 2009 and 2010 - before falling again to $4.0 \%$ in 2011. ${ }^{1}$ Four out of five plants were set in a German-speaking region (BerneMittelland) with unemployment rates oscillating around the national average. One plant was set in the French-speaking region of Geneva, where unemployment rates were consistently higher and reached $7 \%$ in 2010 . Note also that the pace of deindustrialisation was slow over this period. Whilst manufacturing jobs decreased in relative terms from $19.3 \%$ of total employment in 2008 to $18.2 \%$ in 2012, in absolute terms the years after 2009 were marked by stability of manufacturing employment. $^{2}$

Although Switzerland does not belong to the European Union, its economy and labour market do not constitute a case sui generis as is often assumed. In effect, the Swiss economy shares many commonalities with Austria and southern Germany, notably a strong reliance on vocational education, a resilient manufacturing sector and low levels of unemployment. As an illustration, the unemployment rates in the adjacent Bundesländer of Austria and Germany were lower in 2011 than in Switzerland-with 3.0\% in Western Austria (comprising Oberösterreich, Salzburg, Tirol and Vorarlberg), 3.3\% in Bavaria and 3.6\% in Baden-Württemberg. ${ }^{3}$ It may thus reasonably be expected that a survey on plant closure in Innsbruck, Munich or Stuttgart would produce comparable results to the ones presented here.

Although Switzerland's employment legislation is amongst the most lenient in the OECD with respect to individual dismissals, ${ }^{4}$ collective dismissals are regulated somewhat more strictly (OECD, 2013, p. 78, 85). Firms dismissing more than $10 \%$ of their workforce must respect an additional delay before notice can be served and they need to consult the work's council. As a result, mass displacements in Switzerland often go along with bargaining over social plans-plans that frequently

\footnotetext{
${ }^{1}$ Rates according to the ILO definition of unemployment and based on the Swiss Labour Market Survey.

${ }^{2}$ In terms of full-time equivalents, manufacturing employment evolved as follows in Switzerland: 661,000 (2008), 629,000 (2009), 626,000 (2010), 633,000 (2011), 636,000 (2012). Data for third semester; source: Swiss Federal Office of Statistic, BESTA/STATEM statistics.

${ }^{3}$ Data provided by Eurostat on: http://epp.eurostat.ec.europa.eu/statistics_explained/index.php/ Unemployment_statistics_at_regional_level (accessed 18 February 2014).

${ }^{4}$ The notice period of dismissal is one month in the first year of tenure, two months after 1 to 9 years of tenure and three months after 10 years of tenure. There is no severance pay and little procedural inconvenience.
} 
include provisions on termination pay and early retirement. The official retirement age in Switzerland is 64 years for women and 65 for men-with very little incentives from the state pension system to retire early.

Employment protection in Switzerland is weak, but unemployment insurance works comparatively well as a buffer against income loss. A contribution period of at least 18 months entitles workers to a benefit period of 18 months with a replacement rate of $70 \%$ of the last wage ( $80 \%$ for low-wage earners and job seekers with dependent children). For workers aged 55 years or older, a contribution period of 24 months entitles to unemployment benefits during 24 months. In parallel, unemployed workers benefit from active labour market measures such as job search counselling or training programmes and are strictly monitored.

We ran our survey in autumn 2011 with the goal of obtaining information on displaced workers' employment status 1.5 to 2.5 years after they had lost their job. There is some variation in the month in which workers left their plant. On average, workers responded to our survey 24 months after their displacement. For $50 \%$ of the respondents (percentile 25 to percentile 75 ) the survey took place between 19 and 29 months after displacement. Unlike the Displaced Worker Survey (DWS) in the USA, we do not adopt the restrictive definition of the Bureau of Labor Statistics, which only considers employees with at least 3 years of tenure as displaced workers. On the contrary, we sent a questionnaire to all the valid addresses- $90 \%$ of the workforce of the five plant closures-which left us with 1,203 displaced workers, both high- and low-tenured ones. Overall, 748 individuals responded to our mixed-mode survey: $77 \%$ on paper, $21 \%$ on the Internet and $2 \%$ by phone. This represents a net response rate of $62 \%$.

For both respondents and non-respondents, we obtained further information on socio-demographic characteristics and the employment status by adding administrative data from the unemployment insurance register $(n=357)$ and firm-internal data $(n=600)$. Our final database thus combines information from three sources: the survey, the unemployment register and the firms. Altogether, this leaves us with some information on the post-displacement experience of 887 displaced workers (74\% of the sample).

Plant closure is probably the best instrument to analyse the effect of job loss on workers' careers. Still, there likely is some selection of workers into plants with a higher propensity to close down. Confronted with a choice, many high-skilled workers may think twice before seeking employment in a debt-ridden plant. Moreover, some workers anticipate the closure of their plant and leave their jobs before the closure is officially announced (Schwerdt, 2011). These two effects imply that the most mobile and best employable workers may already have left these plants at the moment of our survey (or never have entered them to begin with). As a consequence, our study is more likely to over- than underestimate the difficulties of displaced workers to find a new job. 
The opposite selection effect may arise from non-response bias. If the same socio-demographic characteristics such as language proficiency or education determine both participation in our survey and successful re-employment after mass displacement, our estimates produce too optimistic findings. Thanks to the register data obtained from the firms, we can examine the non-response bias by comparing the composition of the sampled population and the survey respondents in terms of sex, pre-displacement occupation and nationality. These results suggest that women, Swiss nationals, as well as managers, professionals and technicians are slightly over-represented. In contrast, men, nationals from Kosovo-Albania and workers employed as machine operators and in elementary occupations are slightly under-represented amongst the respondents. However, sensitivity tests ranging from weighting to analysing only parts of the sample suggest that the article's conclusions are untainted by non-response bias (see Baumann et al., forthcoming). ${ }^{5}$

Our main dependent variable is occupational status 1.5 to 2.5 years after displacement, and most of our analyses differentiate between four outcomes: reemployment, unemployment, economic inactivity or retirement. In addition, we examine the sector of re-employment and distinguish between four sectors: (i) manufacturing and construction, (ii) distributive and consumer services, (iii) business services and (iv) social and public services. ${ }^{6}$ A third outcome dimension of interest is job quality as measured with indicators such as contract type, standardised earnings of full-time employees and job satisfaction in the old and new job.

The operationalisation of our independent variables is straightforward. We distinguish between three levels of educational attainment: (i) lower secondary education or less, which includes mandatory schooling up to 10 years; (ii) upper secondary education, which mostly consists of vocational training (apprenticeships) and, to a lesser extent, general degrees such as the Maturite (Abitur/ A-level); (iii) tertiary education, which includes higher vocational degrees, technical college degrees and university degrees. Moreover, we separate white-collar workers (managers, professionals, technicians and clerks) from blue-collar workers (craft workers, machine operators and elementary jobs) on the basis of

\footnotetext{
${ }^{5}$ Two measures make non-response less of a problem for our study. First, we drew an additional sub-sample of workers with a migrant origin from outside the European Union (notably the former Yugoslavia and Turkey) and completed phone interviews with them. Second, we were able to access unemployment register data for those workers who did not respond to our survey and who could be located in this database. Since not all displaced workers went through a spell of unemployment, the register data provided us with information on 139 non-respondents who did not witness a smooth transition after displacement.

${ }^{6}$ Distributive and consumer services include retail trade, transport and postal services, restaurants and hotels and personal services. Business services include financial, legal and IT services, consulting, research and communication. Social and public services include health care, education, social welfare, public administration and public utilities.
} 
their occupation at the moment of displacement. ${ }^{7}$ The influence of age is analysed alternatively as a continuous variable and on the basis of 5-year and 10-year age cohorts. Finally, we control for the labour market context by matching to each worker the official unemployment rate in the plant's district in the last month before displacement. Since not all workers left their plants at the same moment, this provides us with 42 different unemployment rates ranging from $1.7 \%$ to $7.2 \%$. Table A. 1 in the Appendix provides the descriptive statistics of these variables.

\section{Evidence on the post-displacement employment status}

Three issues are at stake in our empirical analysis: who is re-employed, to what sector do the re-employed go and what is the job quality of the new job? In this section, we tackle the first issue and analyse displaced workers' situation 1.5 to 2.5 years after their plant closed down. Table 2 differentiates the employment status of displaced workers by sex, education, occupation and age. Before looking at the influence of these socio-demographic characteristics, we discuss the total distribution, shown in the table's bottom row. Whilst $69 \%$ of workers were back in paid employment, $17 \%$ of displaced workers were still (or again) unemployed and $11 \%$ had gone into retirement (3\% having reached the legal age of retirement, whereas $8 \%$ chose to retire early). Finally, 3\% of workers left the labour market for other reasons such as training, housework or a disability pension.

The comparison by gender suggests that women are more likely to be re-employed than men. Approximately 2 years after displacement, $75 \%$ of women were back in a job as compared with only $68 \%$ amongst men. However, contrary to our hypothesis, this difference does not arise because men are at greater risk of staying unemployed, but because they are more likely to retire early than women. To some extent, this is due to men's higher average age at the moment of displacement: 46.3 years as compared with 42.3 years for women. Moreover, men are likely to have acquired higher pension entitlements over their working careers than women, making early retirement a more financially viable option. In effect, $9 \%$ amongst displaced men, but only $1 \%$ amongst displaced women retired early.

When turning to education, Table 2 shows that highly educated workers were more likely than less educated workers to be re-employed and retired, but less likely to still be unemployed or to have left the labour force. However, the difference is small as even amongst workers with lower secondary education $66 \%$ returned to a job-only 6 percentage points less than the re-employment rate of

\footnotetext{
${ }^{7}$ ISCO-88 three-digit codes 100 through 412 and 414 through 430 are defined as white-collar occupations, whereas codes 413 and 600 through 940 are defined as blue-collar occupations. The lower service occupations (codes 500 through 530) would probably best be defined as 'pink-collar occupations'. However, since our industrial plants did not employ any of these occupations, this third category is of no relevance in this study.
} 
Table 2 Employment status of displaced workers 1.5 to 2.5 years after plant closure (\%)

\begin{tabular}{llllll}
\hline & & Employed & Unemployed & Inactive & Retired \\
\hline \multirow{3}{*}{ Sex } & Women & 75 & 17 & 5 & 4 \\
\multirow{5}{*}{ Education } & Men & 68 & 17 & 2 & 12 \\
& Lower secondary or less & 66 & 22 & 5 & 7 \\
& Upper secondary & 70 & 18 & 3 & 10 \\
& Tertiary & 72 & 13 & 0 & 15 \\
\multirow{5}{*}{ Agcupation (years) } & Blue-collar & 68 & 19 & 3 & 9 \\
& White-collar & 71 & 13 & 2 & 14 \\
& 29 and younger & 86 & 7 & 7 & 0 \\
& $30-39$ & 90 & 8 & 2 & 0 \\
& $40-49$ & 87 & 12 & 0 & 0 \\
& $50-54$ & 82 & 15 & 3 & 0 \\
& $55-59$ & 53 & 30 & 3 & 15 \\
\multirow{5}{*}{ Total } & 60 and older & 12 & 34 & 3 & 51 \\
& & 69 & 17 & 3 & 11 \\
\hline
\end{tabular}

Note: Rows add up to $100 \%$. Pearson chi-square tests indicate that there is a significant relationship between the employment status on the one hand and sex, education, occupation, age on the other $(P<0.01) . N$ : 887 (total), 886 (sex), 853 (education), 872 (occupation, age).

workers with a tertiary degree. The gap is larger with respect to unemployment: $22 \%$ of the low educated, but only $13 \%$ of the highly educated were still unemployed about 2 years after plant closure.

The re-employment rates of white- and blue-collar workers are similar: $71 \%$ for the former as compared with $68 \%$ for the latter. The difference between the two categories is more consequential with respect to unemployment and retirement: bluecollar workers were more likely to be unemployed (19\% as compared with $13 \%$ ), whereas white-collar workers went more often into retirement (14\% as compared with 9\%). Again, the difference amongst the retired is entirely due to early retirement: $11 \%$ of white-collar workers but only $6 \%$ of blue-collar workers decided to retire early.

We observe the largest disparity in employment rates when comparing age cohorts. Amongst workers below 55 years, over $80 \%$ had found a job about 2 years after plant closure. Amongst prime-aged workers between 30 and 49 years, the re-employment rate even rises to over $87 \%$. The contrast with older workers is stark: amongst displaced workers aged 55 to 59 , only $53 \%$ had returned to paid employment. In the age group of 60 - and 65 -year-olds, those finding a job represent a mere $13 \%$. Whilst retirement explains some of these differences, the gap in unemployment rates looms large. $49 \%$ of the oldest and $15 \%$ of the second-oldest age cohort opted for early retirement, but in parallel 30\% (age 55-59) and 36\% (age 60-65) remained unemployed. This finding is not trivial: consistent with the idea that contracting firms and declining occupations have an older age 
structure (Autor and Dorn, 2009), the two age categories of 55-59 and 60-65 are large and make up, together, $30 \%$ of our sample.

The bivariate analysis in Table 2 is possibly misleading, as women may be more likely to find work than men because they are younger, or older cohorts may struggle more in their job search because they are less educated than younger cohorts. Therefore, we estimate the net influence of socio-demographic factors such as age or education on re-employment in a multi-nomial logistic regression model. Our dependent variable is the post-displacement employment status where we only distinguish three outcomes: (i) gainfully employed, (ii) unemployed or inactive or (iii) retired. We combine the unemployed and inactive into the same category because multi-nomial logit models only work if categories of the dependent variables are distinct alternatives, not close substitutes (Long and Freese, 2006). Our survey contains information on the number of applications sent to employers and suggests that a majority of the inactive put great effort into finding a job, and finally left the labour force because of discouragement.

The independent variables include sex, education, occupational group and age. Because the workforces of our five companies differ in their re-employment ratesworkers in the French-speaking company were more likely to be still unemployedwe add controls for the former company as well as for the official unemployment rate in the plant's district in the month before displacement (coefficients not shown). Finally, we correct for the fact that our data are nested at the firm level by using clustered standard errors.

Table 3 presents the results for the probability of being employed compared with the probability of being unemployed or inactive (not showing the results related to retirement). We estimate four models where we first introduce sex, before step-wise adding education, occupational group and age. Sex matters once we combine the unemployed and inactive in a sole category and control for age, education and occupation. Men are more likely to return to a job and less likely to be either unemployed or inactive than women. In addition, a tertiary degree clearly improves the odds of finding a job. This is also the case for upper secondary education compared with not having any upper secondary schooling, but the effect is weaker. Likewise, for a given education and age, white-collar employees are more likely to be re-employed than are blue-collar workers. Finally, age is very consequential. Even when accounting for differences in sex, education and occupational group, the two oldest cohorts (aged 55-59 and 60-65) are much more likely to remain unemployed. For workers in their mid-fifties, re-employment rates drop steeply. The importance of age is also evident from a look at the pseudo $R^{2}$ : whilst education and occupation only marginally affect the model's fit of our data, introducing age leads to a strong increase.

Comparing the coefficients of logistic regressions across models with different independent variables is hazardous. We therefore calculate the predicted probabilities 
Table 3 Multi-nomial logistic regression coefficients for the probability of re-employment relative to unemployment/inactivity

\begin{tabular}{|c|c|c|c|c|c|c|c|c|c|}
\hline & & \multicolumn{2}{|c|}{ Model 1} & \multicolumn{2}{|c|}{ Model 2} & \multicolumn{2}{|c|}{ Model 3} & \multicolumn{2}{|l|}{ Model 4} \\
\hline & & Coef. & SE & Coef. & SE & Coef. & SE & Coef. & SE \\
\hline Sex & Men & 0.16 & 0.25 & 0.08 & 0.22 & 0.17 & 0.27 & $0.48^{*}$ & 0.22 \\
\hline Education & Upper secondary & & & 0.50 & 0.32 & 0.38 & 0.29 & $0.79 *$ & 0.31 \\
\hline (ref: lower secondary) & Tertiary & & & $1.08 *$ & 0.21 & $0.74 *$ & 0.09 & $1.13^{*}$ & 0.11 \\
\hline Occupation (ref: white-collar) & Blue-collar worker & & & & & $-0.57^{\star}$ & 0.25 & $-0.65^{*}$ & 0.29 \\
\hline \multirow[t]{8}{*}{ Age in years (ref: 45-49) } & $16-24$ & & & & & & & -0.26 & 0.56 \\
\hline & $25-29$ & & & & & & & -0.13 & 0.42 \\
\hline & $30-34$ & & & & & & & -0.05 & 0.42 \\
\hline & $35-39$ & & & & & & & 0.58 & 0.38 \\
\hline & $40-44$ & & & & & & & -0.09 & 0.29 \\
\hline & $50-54$ & & & & & & & -0.23 & 0.43 \\
\hline & $55-59$ & & & & & & & $-1.61 *$ & 0.36 \\
\hline & 60 and older & & & & & & & $-3.34^{\star}$ & 0.48 \\
\hline Constant & & -0.79 & 1.12 & -1.55 & 1.48 & -0.53 & 1.71 & -0.99 & 1.51 \\
\hline Pseudo $R^{2}$ & & \multicolumn{2}{|c|}{0.11} & \multicolumn{2}{|c|}{0.12} & \multicolumn{2}{|c|}{0.12} & \multicolumn{2}{|c|}{0.44} \\
\hline$N$ & & \multicolumn{2}{|c|}{782} & \multicolumn{2}{|c|}{782} & \multicolumn{2}{|c|}{782} & \multicolumn{2}{|c|}{782} \\
\hline
\end{tabular}

Note: The dependent variable is multi-nomial and differentiates between three outcomes: (i) employed, (ii) unemployed or inactive, (iii) retired. The coefficients for the probability of being retired are not shown here (they are strongly determined by age). All models include controls for former company and the unemployment rate of the district in the month of displacement. Standard errors are clustered at the firm level. * Significant at $P<0.05$. 


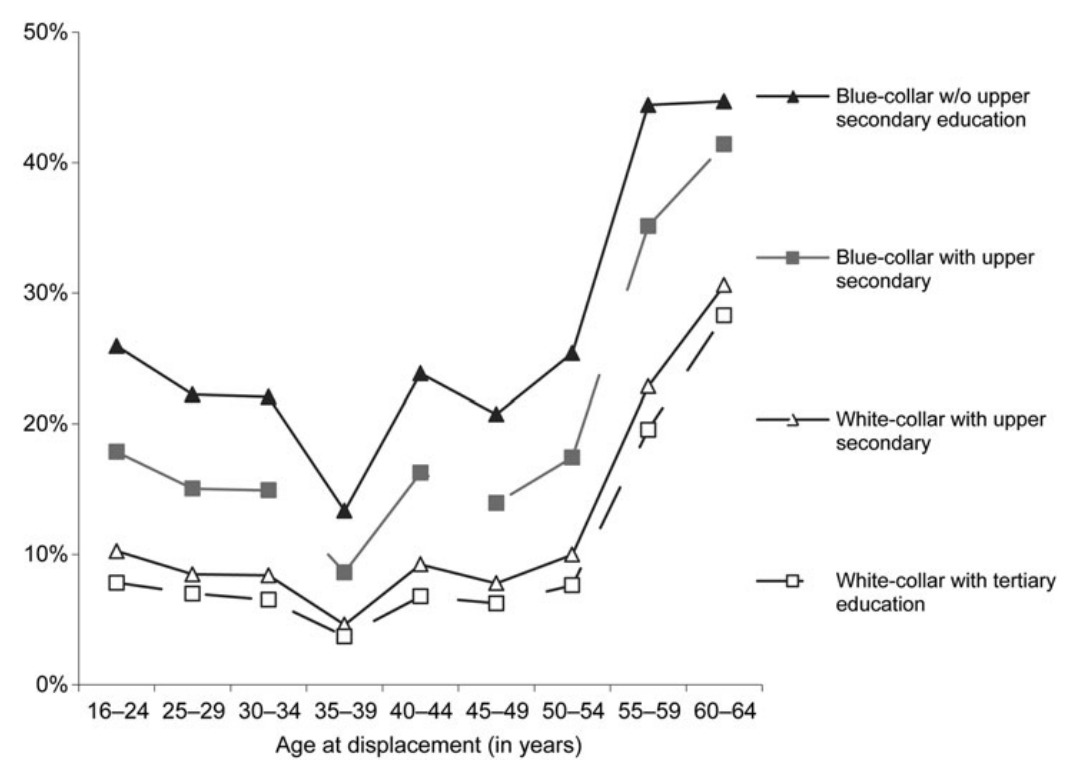

Figure 1 Predicted probabilities for a man to still be unemployed or inactive (and not being employed or retired-based on the coefficients of Table 3, Model 4).

of remaining unemployed or inactive for a given worker profile on the basis of the complete multi-nomial regression shown in Table 3. These probabilities are plotted in Figure 1 and reveal how the likelihood of being unemployed or inactive varies according to education, occupational group and age for a man (the modal category, men accounting for $83 \%$ of our sample).

Amongst low-educated blue-collar workers below 55 years, between $20 \%$ to $25 \%$ were unemployed or inactive 2 years after mass displacement. The unemployment rate falls to between $14 \%$ and $18 \%$ for medium-educated blue-collar workers below 55 years. It is even lower amongst white-collar workers below 55 years where the share of the unemployed oscillates between $6 \%$ and $10 \%$, with a small advantage for those employees with tertiary education.

Regardless of people's education and colour of collar, being 55 years or older at the moment of displacement constitutes a massive handicap for re-employment. In the age cohort of 55-59 years, unemployment concerns $23 \%$ of medium-educated white-collar employees and $35 \%$ of medium-educated blue-collar workers. Clearly, education and a former white-collar position do not insulate older workers from long spells of unemployment.

Could the age effect be due to the welfare state rather than the labour market-as welfare provisions make it attractive for older workers to remain unemployed and wait for retirement? This hypothesis seems unlikely for three reasons. First, unemployment benefits for workers aged 55 and older are limited to 2 years-and 
there are weak pension incentives to retire early in Switzerland (OECD, 2011, p. 55). Without an employer-financed early retirement as contained in some social plans, it is difficult to wait out the years until regular retirement without working. Second, our survey shows that unemployed workers aged 55 and older were putting great effort into finding a job: $26 \%$ of them had applied for between 50 and 100 jobs and $46 \%$ for more than 100 jobs. Third, satisfaction with life decreases more for the unemployed aged between 55 and 59 ( -3.4 points on a scale from 0 to 10 ) than for the unemployed on average ( -2.8 points). This large fall in well-being suggests that the bulk of unemployment amongst older workers is involuntary.

Still, except for the two oldest age cohorts, we do not find much evidence for the gloomy expectation in political economy that displaced industrial workers are condemned to persistent unemployment. To what extent do these findings from Switzerland, where unemployment has traditionally been low, apply to other countries? A detailed analysis of the US Displaced Worker Surveys 1984-2000 finds the reemployment rate for displaced mid-age, medium-educated male manufacturing workers in the United States to be between 62\% and 65\% in 1989 (Kletzer, 2001, p. 45). A Finnish study run in 2008 on displaced manufacturing workers finds that 10 months after plant closure $62 \%$ of the respondents were in paid work again, $19 \%$ in education or training, $14 \%$ unemployed and $5 \%$ had left the labour market (Jolkkonen et al., 2012, p. 88). Age, but not education, was singled out as a strong risk factor in Finland: the odds of being unemployed were 11 times higher for displaced workers over 50 years than for those under 35 years (Jolkkonen et al., 2012, p. 90). A large multi-country study coordinated by Kuhn (2002, p. 31) confirms that older workers fare worse than younger workers after displacement both in terms of re-employment and wages.

Of course, our re-employment rate of $69 \%$ can by no means be generalised to countries and periods with higher aggregate unemployment than Switzerland between 2009 and 2011. This argument draws on Appelqvist (2007) who shows the powerful influence of the business cycle on re-employment rates following plant closure in Finland during the 1990s and 2000s. Likewise, Kletzer (2001, p. 49) finds large differences in displaced workers' reemployment rates in the USA between the recession years 1981-83 and the boom period 1993-99.

\section{The sector of re-employment}

Results on re-employment rates suggest that-with the exception of the oldest cohorts-industrial workers fare better than what the political economy hypothesis based on a 'thick skill boundary' expects. Why is this hypothesis too pessimistic? An analysis of the sectors of re-employment gives a tentative answer and shows that only a minority of $35 \%$ of re-employed workers move on to services: for $13 \%$ of re-employed workers the new job was in social and public services, for 
$12 \%$ in distributive and consumer services and for $10 \%$ in business services. Both re-employed men (66\%) and re-employed women (57\%) were more likely to return to a job in manufacturing and construction. Although manufacturing accounts for less than a fourth of Switzerland's employment in 2011, two thirds of displaced industrial workers found again a job in this sector.

A better understanding of structural change prompts the question of who moves on to the service sector and who returns to manufacturing. We examine this issue by estimating a multi-variate model for the sector of employment. Since not all displaced workers returned to a job, the re-employed workers are a selective group and an analysis of sector employment may be tainted by this selection bias. We check for this possibility by resorting to the Heckman correction or, more precisely, to a bivariate probit model with selection correction (using the Stata command heckprob). This implies that we jointly estimate a selection equation on returning to a job and a regression equation on the sector of employment—manufacturing versus services - conditional on re-employment. For this selection model to work, we need an instrumental variable which affects the selection equation (re-employment), but not the regression equation (the sector of employment). In our case, age is such an instrument: it is strongly correlated with re-employment prospects, but has no effect on the sector of employment. ${ }^{8}$

The result of this bivariate probit model with selection correction is shown in Table A.2 in the Appendix. Neither education nor occupational group seem to explain why people decide to accept a job in services rather than to return to manufacturing. The only socio-demographic characteristic significantly increasing the likelihood of a sector shift is sex: for a given education and former occupation, women are more likely to move to a service job than men.

Our analysis of a sector shift may be hampered by treating services as a unitary block, as the service sector encompasses very different industries in terms of average skill requirements and pay levels. We thus divide the service sector into three subsectors: (i) distributive and consumer services, (ii) business services and (iii) social and public services. We then estimate a multi-nomial logistic model on the determinants of being re-employed in either one of these three subsectors as compared with manufacturing. Furthermore, for this analysis it proves fruitful to distinguish two types of tertiary education: tertiary vocational and tertiary general degrees.

The results of this regression are shown in Table 4 and suggest that being a woman and having low levels of education increases the likelihood of taking on employment in distributive and consumer services compared with returning to manufacturing. In

\footnotetext{
${ }^{8}$ Regressing age (in years) on re-employment (yes/no) gives us the following coefficient: 0.104 (standard error: 0.012, $P$-value: 0.000 ). Regressing age (in years) on sector of employment (manufacturing/ services) gives us the following coefficient: -0.0009 (standard error: 0.0087, $P$-value: 0.921 ).
} 
Table 4 Multi-nomial logistic regression coefficients for the probability of re-employment in a service subsector relative to manufacturing

\begin{tabular}{|c|c|c|c|c|c|c|c|}
\hline & & \multicolumn{2}{|c|}{$\begin{array}{l}\text { Distributive and con- } \\
\text { sumer services }\end{array}$} & \multicolumn{2}{|c|}{ Business services } & \multicolumn{2}{|c|}{$\begin{array}{l}\text { Social and public ser- } \\
\text { vices }\end{array}$} \\
\hline & & Coef. & SE & Coef. & SE & Coef. & SE \\
\hline Sex (ref. woman) & Man & $-0.84^{*}$ & 0.18 & -0.10 & 0.62 & -0.38 & 0.91 \\
\hline Education & Upper secondary & -0.30 & 0.25 & -0.04 & 0.38 & -0.38 & 0.50 \\
\hline (ref. no upper & Vocational tertiary & $-0.68^{\star}$ & 0.34 & 0.14 & 0.46 & -0.30 & 0.65 \\
\hline secondary) & General tertiary & -0.34 & 0.55 & 0.58 & 0.33 & 0.45 & 0.50 \\
\hline Occupation (ref. white-collar) & Blue-collar & 0.05 & 0.38 & -0.16 & 0.28 & $-0.82^{\star}$ & 0.25 \\
\hline Age & & 0.01 & 0.02 & 0.00 & 0.01 & 0.01 & 0.01 \\
\hline Constant & & 0.99 & 1.69 & -2.34 & 2.01 & -0.67 & 2.01 \\
\hline
\end{tabular}

Note: $N=507$, pseudo $R: 0.046$. The dependent variable is multi-nomial and distinguishes four outcomes: re-employment in (i) manufacturing and construction (reference category), (ii) distributive and consumer services, (iii) business services and (iv) social and public services. The model includes controls for former company and the unemployment rate of the district in the month of displacement. Standard errors are clustered at the firm level. *Significant at $P<0.05$. 


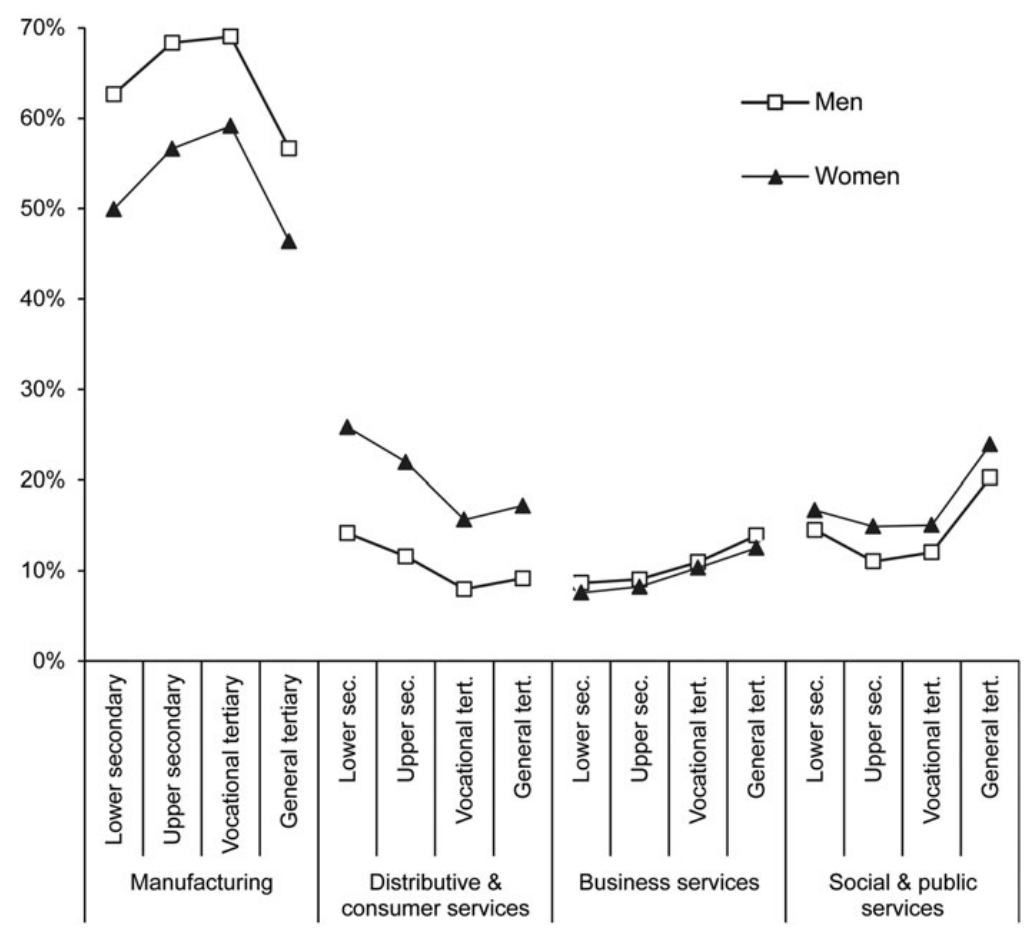

Figure 2 Predicted probabilities of being re-employed in a given sector by sex and education (based on the models of Table 4).

contrast, white-collar employees are much more likely than blue-collar workers to shift to social and public services than to stay in manufacturing.

To give a better idea of how education and sex affect the likelihood of a sector shift, we plot in Figure 2 the model's predicted probabilities of being re-employed in a given subsector. Different levels of education lead to strongly diverging employment patterns across sub-sectors. The likelihood of returning to a manufacturing job is substantially higher for workers with intermediary levels of educationthose with upper secondary education (usually an apprenticeship) or vocational tertiary education - than for those with lower or higher education. This suggests that the (specific) skills of vocationally trained workers are more strongly geared towards manufacturing than those of either low educated or university-trained workers.

Within the service sector, the educational profile differs markedly between subsectors. Whilst social and public services as well as business services disproportionally attract workers with higher education, distributive and consumer services primarily provide jobs for the low educated. Workers without upper secondary education are almost twice as likely to end up in distributive and consumer services 
as workers with a tertiary degree. In business services, the likelihood of finding a job linearly increases with growing education. Social and public services present the opposite educational pattern to manufacturing: not medium-educated workers with vocational education but either low-educated or, above all, highly educated workers with a general tertiary degree are over-represented in this subsector.

If we add the differences by sex, our results suggest that men with intermediary vocational education disproportionately return to a job in manufacturing. In contrast, low-educated women disproportionately go to jobs in distributive and consumer services and highly educated women to jobs in social and public services.

Schematically, we thus find distributive and consumer services to be the low-end destination of displaced workers, whereas social and public services appears as the high-end destination-both sub-sectors disproportionately catering to women. Business services and manufacturing are the intermediate categories, with the latter being biased in favour of men. This distinction of four qualitatively different destinations is also evident from a look at wages. When expressing the hourly postdisplacement wage for each sector as a multiple of the total mean, we obtain a value of 0.91 for distributive and consumer services, 0.97 for business services, 1.00 for manufacturing and 1.10 for social and public services.

\section{The quality of the post-displacement job}

Our survey data show that two thirds of displaced workers had found another job about 2 years after their plant closed down. However, finding a job and finding an adequate job are different matters. Accordingly, a last set of analyses examines the quality of post-displacement jobs. A first indicator is the contract type: $86 \%$ of re-employed workers had a permanent contract and 14\% a fixed-term contract in their new job. The low proportion of fixed-term contract holders needs to be seen in the context of Switzerland's weak employment protection. Still, this result suggests that the great majority of re-employed workers returned to stable jobs.

Arguably, the most relevant indicator of job quality are wages. The combination of our survey and administrative data provides us with information on wages in the job before as well as the job after displacement for close to 400 individuals. The existence of two time points allows us to take a within-person (fixed-effect) measure: the percentage change in full-time workers' hourly wages before and after displacement. ${ }^{9}$ Since this fixed-effect measure only uses variation within the same

\footnotetext{
${ }^{9}$ We only consider the wages of people who work 35 hours or more in the old and the new job because information on working hours for part-timers does not seem robust and hence information on hourly wages for this (small) sub-group is not trustworthy. Wages are standardized for 40 hours per week. People with no wages (living on unemployment or retirement benefits) are not included in this analysis.
} 
individual over time, it takes care of potential selection into employment (Halaby, 2004, p. 530).

On average, the hourly wage decreased by $2.5 \%$ for those displaced workers who succeeded in returning to a job. However, there is substantial variance. For the unluckiest $25 \%$ of re-employed workers, the wage loss exceeded $11 \%$. In contrast, the luckiest $25 \%$ of re-employed workers experienced wage gains of $7 \%$ and more. A look at the hourly wages of sub-groups reveals that, on average, men lost out more than women $(-3 \%$ versus $+3 \%)$, low- and medium-educated workers more than their high-educated colleagues (both $-4 \%$ as compared to $+1 \%$ ) and bluecollar workers more than white-collar employees $(-5 \%$ versus $+1 \%)$. Again, the disparity is largest between age cohorts: on average, young workers substantially increased their hourly wages $(+8 \%$ and $+9 \%$ for those aged $16-24$ and $25-29)$, whereas re-employed older workers had to accept massive wage cuts: $-12 \%$ (55$59)$ and $-15 \%(60-65)$. Older workers thus need to toil 1.5 to 2 months longer in the new job to attain the same yearly income as the one they had in the old job.

We analyse the influence of different socio-demographic characteristics on wage change by estimating a linear regression model. The results are shown in Table 5 and suggest that the same factors hampering re-employment also lead to lower wages. Between the old and the new job, wages of blue-collar workers decrease by $5 \%$ relative to those of white-collar workers. Similarly, almost all age cohorts lose out with respect to the cohorts aged 29 years or less. Particularly large is the wage cut for re-employed workers aged 55 or older: relative to the change witnessed by the youngest cohort, their hourly wages fall by $20 \%$. Once we control for other characteristics, education has no impact on wage change and the effect of sex does not reach statistical significance (although the coefficient suggests that men had to accept larger wage cuts than did women). The standard errors for sub-sectors are also too large for the coefficients to be statistically significant. Still, they clearly suggest that relative to workers returning to manufacturing, workers moving to business services or social and public services increased their wages, whereas workers moving to distributive and consumer services saw their wages decrease. In other words, displaced workers who took on a job in distributive and consumer services were more likely to lose out in terms of wages than workers securing a job in business services or social and public services. We thus find again evidence for a service sector divided into low-end and high-end destinations.

Contract type and wages are not the only relevant dimensions of job quality. Our survey also asked displaced workers to indicate their satisfaction with the old and the new job on a scale from 0 (totally dissatisfied) to 10 (totally satisfied). A comparison of re-employed workers' satisfaction with the old and new job shows a significant drop from a mean value of 7.6 (old job) to 6.9 (new job). The drop was stronger for older workers than for young workers, for low-educated than for highly educated workers and for workers returning to manufacturing than for 
Table 5 OLS regression coefficients showing the average within-person wage change between the job before and after displacement

\begin{tabular}{llcc}
\hline & & Coef. & SE \\
\hline Sex (ref. women) & Men & -0.05 & 0.02 \\
Education & Upper secondary & 0.01 & 0.01 \\
(ref. lower secondary) & Tertiary & 0.02 & 0.01 \\
Occupation (ref. white-collar) & Blue-collar worker & $-0.05^{*}$ & 0.01 \\
Age in years (ref. 16-24) & $25-29$ & 0.02 & 0.04 \\
& $30-34$ & -0.07 & 0.03 \\
& $35-39$ & $-0.08^{*}$ & 0.03 \\
& $40-44$ & -0.08 & 0.03 \\
& $45-49$ & -0.08 & 0.05 \\
& $50-54$ & $-0.12^{*}$ & 0.02 \\
& $55-59$ & $-0.19^{*}$ & 0.03 \\
Sector (ref. manufacturing) & 60 and older & $-0.22^{*}$ & 0.05 \\
& Distributive and consumer services & -0.02 & 0.02 \\
Constant & Business services & 0.04 & 0.02 \\
$R^{2}$ & Social and public services & 0.08 & 0.05 \\
$N$ & & 0.13 & 0.16 \\
& & \multicolumn{2}{c}{0.16} \\
\hline
\end{tabular}

Note: The model includes controls for former company and for the unemployment rate of the district in the month of displacement. Standard errors are clustered at the firm level. * Significant at $P<0.05$.

those finding a job in social and public services. The pattern thus strongly resembles the results for changes in wages.

Finally, finding an adequate job may impose long commutes on displaced workers. In fact, the majority of those workers who were re-employed spend more time commuting to their new job than they did to their old job. Whilst the commuting time remained unchanged for $22 \%$ and even decreased for $27 \%$ of re-employed workers, $27 \%$ declare spending slightly more time commuting to work than before (an increase of 5 to 30 minutes or more per way) and $24 \%$ a lot more time (an increase of over 30 minutes).

Overall, working conditions of re-employed workers thus seem to have become less advantageous - be it in terms of wages or job satisfaction. However, primarily older and blue-collar workers had to put up with a less favourable employment relationship than before plant closure, whereas younger workers and white-collar employees were able to hold their ground.

\section{Discussion and conclusion}

This article analysed the destinations to which workers go after their plant closes down. The objective has been to determine the proportion of workers who are 
re-employed, the sector of re-employment and the quality of the new job. Our findings provide us with three main results.

First, a surprisingly large share of the labour force was back in employment 2 years after being laid off. Two out of three displaced workers were re-employed at the moment of the survey. One out of six workers remained unemployed, and one out of nine workers had gone into retirement-most often into early retirement. Clearly, these results come closer to the dynamic labour market model of the job flow literature (Hypothesis 1) than to the political economy view according to which structural change leads to persistent unemployment amongst industrial workers (Hypothesis 3). Contrary to the dead-end view of displaced industrial workers held in political economy, the majority of blue-collar workers did not become long-term unemployed, but had returned to a job in manufacturing. This result throws doubt on the expectation that post-industrial economies can only absorb redundant manufacturing workers if their wage structure is opened downwards to facilitate the creation of low-paid service jobs (Iversen and Wren, 1998). In countries with low unemployment such as Switzerland - and probably also Austria and southern Germany - the constant turnover of workers and jobs implies that even in a stagnant sector such as manufacturing, enough new jobs open up to absorb great numbers of displaced industrial workers. The assumption that low-end services have to serve as a collecting vessel for redundant industrial workers is mistaken.

Second, our analysis only produces lukewarm evidence for skill-biased and sexbiased technological change. Whilst less educated workers fare worse after plant closure than their better educated colleagues, the effect of education on reemployment and, above all, post-displacement wages is much smaller than what the skill-biased technological change hypothesis led us to expect (Hypothesis 4). Over $80 \%$ of low-educated workers below 50 years were back in employment 2 years after mass displacement - and the level of education has a minor effect on wage change between the old and new job. Likewise, we find little evidence for the related expectation that women fare substantially better after displacement than men. However, the political economy hypothesis is correct with respect to the collar divide: being a white-collar worker improves the odds of re-employment and limits the extent of wage losses compared with blue-collar workers.

Third, advanced age appears to be a massive handicap after plant closure. Displaced workers aged between 55 and 59 years (who make up 12\% of our sample) have still between 5 and 10 years to go until they reach the legal retirement age. Yet only half of them were back in paid employment and another third remained unemployed around 2 years after plant closure. Moreover, for those older workers who succeeded in returning to a job, wages dropped, on average, by over $10 \%$. Our analysis thus corroborates the expectation that older workers are the most vulnerable group after mass redundancies (Hypothesis 5). The re-employment difficulties of older workers also imply that cohort renewal, whilst being relevant in 
the shape of early retirement, does not suffice to absorb the structural change caused by plant closures (Hypothesis 2 ).

In sum, this article gives us two insights: one spells good news, one bad news. Good news is that deindustrialisation does not call for the creation of low-wage service jobs to get laid-off blue-collar workers back to work- at least not in Switzerland. Rather, we observe high rates of re-employment in manufacturing. Of course, the good news may be specific to an economic context with moderate unemployment, a sizeable industrial sector and a strong vocational training systemsuch as the context currently prevailing in German-speaking countries. The jury is thus still out on the external validity of our Swiss results.

The bad news is that even in Switzerland, in the aftermath of a plant closure, older workers are very vulnerable to long-term unemployment. Early retirement clauses in post-displacement social plans are no solution to the 'lump-of-labour' fallacy, that is, the idea that an economy has a fixed number of jobs that need to be transferred from the old to the young. However, they may be justified on the basis that being dismissed a few years before reaching retirement age imposes a heavy strain on workers. The policy implication of this finding is evident. When large plants close down, policy efforts should target workers on the basis of age-and active labour market programmes should be designed with older workers in mind. The burden of structural change disproportionately falls on their shoulders.

\section{Acknowledgements}

Earlier versions of this article were presented at the ECSR-conference in Stockholm, the social inequality working group at the EUI in Florence and several meetings with the SECO group "Analysis of Labour Market and Social Policies" in Berne. Particularly helpful were comments by Werner Aeberhardt, Simone Balestra, Fabrizio Bernardi, Giuliano Bonoli Dominique Joye, Rafael Lalive, Emily Murphy, Thomas Ragni, Bernhard Weber, the two anonymous reviewers and the editor in chief, Bruno Amable. We are grateful to them as well as to Oliver Lipps, Jonathan Gast, Roman Graf, Jessica Garcia and Lorenza Visenti for their help with the data.

\section{Funding}

This research was financially supported by the Swiss State Secretariat for Economic Affairs (SECO) and carried out within the National Centre of Competence in Research 'LIVES — overcoming vulnerability: life course perspectives', financed by the Swiss National Science Foundation. The authors are grateful to both institutions.

\section{References}

Appelqvist, J. (2007) Wage and Earnings Losses of Displaced Workers in Finland, VATT Discussion Paper No. 422, Government Institute for Research. 
Autor, D. H. and Dorn, D. (2009) 'This Job Is “Getting Old:” Measuring Changes in Job Opportunities Using Occupational Age Structure', American Economic Association Papers and Proceedings, 99, 45-51.

Bachmann, R. and Burda, M. C. (2009) 'Sectoral Transformation, Turbulence and Labor Market Dynamics in Germany', German Economic Review, 11, 37-59.

Baumann, I., Lipps, O., Oesch, D. and Vandenplas, C. (forthcoming). 'How to Survey Displaced Workers in Switzerland? Sources of Bias and Ways around Them'. In Oris, M., Roberts, C., Joye, D. and Ernst-Stähli, M. (eds) Surveying Vulnerability, New York, Springer.

Berman, E., Bound, J. and Machin, S. (1998) 'Implications of Skill-Biased Technological Change: International Evidence', Quarterly Journal of Economics, 113, 1245-1279.

Black, S. E. and Spitz-Oener, A. (2010) 'Explaining Women’s Success: Technological Change and the Skill Content of Women's Work', Review of Economics and Statistics, 92, 187-194.

Blossfeld, H.-P. (1986) 'Republic of Opportunities in the Federal Germany: A Dynamic Approach to the Study of Period Effects', European Sociological Review, 2, 208-225.

Bonoli, G. (2007) 'Time Matters: Postindustrialization, New Social Risks, and Welfare State Adaptation in Advanced Industrial Democracies', Comparative Political Studies, 40, 495-520.

Cha, Y. and Morgan, S. L. (2010) 'Structural Earnings Losses and Between-Industry Mobility of Displaced Workers, 2003-2008', Social Science Research, 39, 1137-1152.

Chan, S. and Stevens, A. H. (2001) 'Job Loss and Employment Patterns of Older Workers', Journal of Labor Economics, 19, 484-521.

Couch, K. A. and Placzek, D. W. (2010) 'Earnings Losses of Displaced Workers Revisited', American Economic Review, 100, 572-589.

Daniel, K. and Heywood, J. S. (2007) 'The Determinants of Hiring Older Workers: UK Evidence', Labour Economics, 14, 35-51.

DiPrete, T. A. and Nonnemaker, L. K. (1997) 'Structural Change, Labor Market Turbulence, and Labor Market Outcomes', American Sociological Review, 62, 386-404.

Fallick, B. C. (1993) 'The Industrial Mobility of Displaced Workers', Journal of Labor Economics, 11, 302-323.

Fallick, B. C. (1996) 'A Review of the Recent Empirical Literature on Displaced Workers', Industrial and Labor Relations Review, 50, 5-16.

Greenaway, D., Upward, R. and Wright, P. (2000) 'Sectoral Transformation and LabourMarket Flows', Oxford Review of Economic Policy, 16, 57-75.

Halaby, C. (2004) 'Panel Models in Sociological Research: Theory into Practice', Annual Review of Sociology, 30, 507-544.

Iversen, T. (2001) 'The Dynamics of Welfare State Expansion: Trade Openness, Deindustrialization and Partisan Politics'. In Pierson, P. (ed) The New Politics of the Welfare State, Oxford, Oxford University Press, pp. 45-79.

Iversen, T. and Cusack, T. R. (2000) 'The Causes of Welfare State Expansion: Deindustrialisation or Globalization?', World Politics, 52, 313-349. 
Iversen, T. and Wren, A. (1998) 'Equality, Employment, and Budgetary Restraint: The Trilemma of the Service Economy', World Politics, 50, 507-546.

Jolkkonen, A., Koistinen, P. and Kurvinen, A. (2012) 'Re-employment of Displaced Workers-The Case of a Plant Closing on a Remote Region in Finland', Nordic Journal of Working Life Studies, 2, 81-100.

Kletzer, L. (2001) Job Loss from Imports: Measuring the Costs, Washington, DC, Institute for International Economics.

Knuth, M. and Kalina, T. (2002) 'Early Exit from the Labour Force between Exclusion and Privilege: Unemployment as a Transition from Employment to Retirement in West Germany', European Societies, 4, 393-418.

Korpi, T. and Mertens, A. (2004) 'Training and Industrial Restructuring: Structural Change and Labour Mobility in West Germany and Sweden', International Journal of Manpower, 25, 90-103.

Kriechel, B. and Pfann, G. (2005) 'The Role of Specific and General Human Capital after Displacement', Education Economics, 13, 223-236.

Kuhn, P. (2002) 'Summary and Synthesis'. In Kuhn, P. (ed) Losing Work, Moving on. International Perspectives on Worker Displacement, Kalamazoo, MI, W. E. Upjohn Institute for Economic Research, pp. 1-104.

Lane, J., Stevens, D. and Burgess, S. (1996) 'Worker and Job Flows', Economics Letters, 51, $109-113$.

Long, J. and Freese, J. (2006) Regression Models for Categorical Dependent Variables Using Stata, College Station, TX, Stata Press.

Neal, D. (1995) 'Industry-Specific Human Capital: Evidence from Displaced Workers', Journal of Labor Economics, 13, 653-677.

Nickell, S. (2001) 'Introduction', Oxford Bulletin of Economics and Statistics, 63(Special Issue), 617-628.

OECD (2009) 'How Do Industry, Firm and Worker Characteristics Shape Job and Worker Flows?'. In OECD Employment Outlook, Paris, OECD, pp. 117-163.

OECD (2011) Pensions at a Glance. Retirement-Income Systems in OECD and G20 Countries. Paris, OECD.

OECD (2013) 'Protecting Jobs, Enhancing Flexibility: A New Look at Employment Protection Legislation'. In OECD Employment Outlook, Paris, OECD, pp. 65-126.

Oesch, D. (2013) Occupational Change in Europe. How Technology and Trade Transform the Job Structure, Oxford, Oxford University Press.

Oesch, D. and Rodriguez Menes, J. (2011) 'Upgrading or Polarization? Occupational Change in Britain, Germany, Spain and Switzerland, 1990-2008', Socio-Economic Review, 9, 503532.

Schwerdt, G. (2011) 'Labor Turnover before Plant Closure: “Leaving the Sinking Ship” vs. “Captain Throwing Ballast Overboard”, Labour Economics, 18, 93-101. 
Trotzier, C. (2005) 'Vingt ans de trajectoire après un licenciement collectif', Économie et Sociologie, 56, 257-275.

\section{Appendix}

Table A.1 Descriptive statistics of the variables used in the analysis

\begin{tabular}{|c|c|c|c|}
\hline Variable & Mean & Min & Max \\
\hline Post-displacement status: re-employed & 0.69 & 0 & 1 \\
\hline Post-displacement status: unemployed & 0.17 & 0 & 1 \\
\hline Post-displacement status: retired & 0.11 & 0 & 1 \\
\hline Post-displacement status: inactive & 0.03 & 0 & 1 \\
\hline Sex: male & 0.83 & 0 & 1 \\
\hline Sex: female & 0.17 & 0 & 1 \\
\hline Education3: less than upper secondary & 0.17 & 0 & 1 \\
\hline Education3: upper secondary & 0.56 & 0 & 1 \\
\hline Education3: tertiary & 0.26 & 0 & 1 \\
\hline Blue-collar worker & 0.62 & 0 & 1 \\
\hline White-collar worker & 0.38 & 0 & 1 \\
\hline Age at displacement (in years) & 46.5 & 16 & 65 \\
\hline Age5: $16-29$ & 0.11 & 0 & 1 \\
\hline Age5: $30-39$ & 0.15 & 0 & 1 \\
\hline Age5: $40-49$ & 0.29 & 0 & 1 \\
\hline Age5: $50-59$ & 0.28 & 0 & 1 \\
\hline Age5: 60 and older & 0.17 & 0 & 1 \\
\hline District unemployment rate in month before displacement & 0.041 & 0.017 & 0.072 \\
\hline Company 1 & 0.12 & 0 & 1 \\
\hline Company 2 & 0.20 & 0 & 1 \\
\hline Company 3 & 0.27 & 0 & 1 \\
\hline Company 4 & 0.25 & 0 & 1 \\
\hline Company 5 & 0.17 & 0 & 1 \\
\hline Fixed-term contract & 0.14 & 0 & 1 \\
\hline Permanent contract & 0.86 & 0 & 1 \\
\hline Monthly wage in pre-displacement job (in CHF)* & 6531 & 2247 & 15,476 \\
\hline Monthly wage in post-displacement job (in CHF)* & 6148 & 2051 & 16,507 \\
\hline Job satisfaction in pre-displacement job (scale $0-10$ ) & 7.69 & 0 & 10 \\
\hline Job satisfaction in pre-displacement job (scale $0-10$ ) & 6.91 & 0 & 10 \\
\hline
\end{tabular}

*Gross monthly wage of full-time employees standardized for 40 h of weekly employment, including an eventual share of a 13 th monthly salary 
Table A.2 A bivariate probit model with selection correction for the probability of re-employment in the service sector relative to manufacturing, conditional on being re-employed

\begin{tabular}{|c|c|c|c|c|c|}
\hline & & \multicolumn{2}{|c|}{$\begin{array}{l}\text { Probit estima- } \\
\text { tion on sector of } \\
\text { employment } \\
\text { (manufactur- } \\
\text { ing/services) }\end{array}$} & \multicolumn{2}{|c|}{$\begin{array}{l}\text { Selection equa- } \\
\text { tion on re- } \\
\text { employment } \\
\text { (no/yes) }\end{array}$} \\
\hline & & Coef. & SE & Coef. & SE \\
\hline Sex (ref. woman) & Men & $-0.37 *$ & 0.16 & 0.20 & 0.15 \\
\hline Education & Upper seconday & 0.004 & 0.19 & $0.80 *$ & 0.15 \\
\hline (ref. no upper secondary) & Tertiary & -0.005 & 0.19 & $1.00 *$ & 0.14 \\
\hline Occupation (ref. white-collar) & Blue-collar & -0.10 & 0.09 & $-0.31 *$ & 0.06 \\
\hline \multirow[t]{8}{*}{ Age in years (ref. 16-24) } & $25-29$ & & & -0.30 & 0.34 \\
\hline & $30-34$ & & & -0.05 & 0.31 \\
\hline & $35-39$ & & & -0.02 & 0.21 \\
\hline & $40-44$ & & & 0.09 & 0.39 \\
\hline & $45-49$ & & & -0.02 & 0.17 \\
\hline & $50-54$ & & & -0.28 & 0.28 \\
\hline & $55-59$ & & & $-0.96^{\star}$ & 0.24 \\
\hline & 60 and older & & & $-2.24^{\star}$ & 0.20 \\
\hline Constant & & 0.71 & 0.57 & -0.48 & 0.49 \\
\hline Rho & & 0.11 & 0.11 & & \\
\hline
\end{tabular}

Note: $N$ observations: 793; censored observations: 313 . The selection equation contains the same variables as Model 4 in Table 3. Coefficients vary slightly as we have information on the sector of employment for only $81 \%$ of the re-employed workers. Accordingly, this selection equation is based on a smaller sample. The model includes controls for former company and for the unemployment rate of the district in the month of displacement. Standard errors are clustered at the firm level. *Significant at $P<0.05$. 